\title{
Motion Descriptions in English and Greek: A Cross-Typological Developmental Study of Conversations and Narratives*
}

\author{
Stathis Selimis/Demetra Katis (Athens)
}

\begin{abstract}
Theoretical claims about typologically constrained differences in how speakers habitually describe physical motion are tested through three cross-linguistic developmental studies. Three types of data are analyzed in Greek and English, languages here characterized respectively as Verb- and Satellite-framed in the coding of motion: spontaneous conversations between adults and children aged 1;8-4;6 as well as two types of narratives elicited through pictures and a film from 4-, 7-, 10-year olds and adults. Results show, on the one hand, largely predictable cross-linguistic differences, with overall greater attention paid to manner in English than in Greek and different patterns for coding path. On the other hand, the very appearance as well as intensity of typological effects also depend upon various interacting factors: the precise ways of measuring them, the age of speakers, type, content and communicative exigencies of the discourse as well as the detailed structural characteristics of a language.
\end{abstract}

\section{$1 \quad$ Introduction}

It has been repeatedly shown that languages code motion event components in strikingly different, though typologically constrained, ways (e. g. Slobin 2000, 2003, 2004a, 2004b, 2006; Talmy 1985, 1991, 2000). Some languages typically code manner in the verb's root and path in satellites, i. e. elements which are in a sister relation to the verb like English particles (e. g. fly + out in example (1)).

(1) The bird flew out of her cage.

In contrast, other languages lexicalize path in the verb and code manner in other elements of the verb phrase such as participles and adverbs (cf. sortir 'exit' + en volant 'flying' in French, example (2); its literal translation into English, 'The bird exited from her cage by flying', is quite unnatural).

(2) L' oiseau est sorti de sa cage en volant.

The different options offered to speakers by their language have been found to strongly influence how they usually verbalize motion events in many studies, mostly of narratives elicited through pictures (cf., e. g., papers in Berman/Slobin 1994 and Strömqvist/Verhoeven 2004; Cardini 2008; Hickmann 2003; Özçalışkan/Slobin 1999, 2001, 2003; Slobin 1996a, 1996b, 1997, 2000, 2003, 2004a, 2006).

More specifically, speakers of Satellite-framed languages (henceforth S-framed or Manner), such as English, German and Russian, lexicalize manner through the verb and describe path

\footnotetext{
* The original studies are included in the first author's doctoral dissertation, whose research was co-financed by the European Social Fund and Greek National Resources (research grant 70/3/7144 of the University of Athens Research Funding Committee). The data on narratives were collected within the CNRS APN 2JE 454 project on the acquisition of discourse in L1 and L2 learners under the responsibility of Marzena Watorek (University of Paris VIII). We thank our reviewers for comments, Vicky Kantzou for her transcription of the Greek data and, above all, Henriëtte Hendriks, of the University of Cambridge, who provided us with the English narratives of Studies 1 and 2.
} 
by means of additional elements such as particles, prefixes and prepositional phrases. By contrast, speakers of Verb-framed languages (henceforth V-framed or Path), such as Spanish, French, Italian, Hebrew and Turkish, tend to encode path in the verb root more often than Slanguage speakers and do not thus typically find it necessary to expand upon path information through peripheral to the verb means. They also provide overall restricted manner information, not only because they lexicalize it less often through the verb but also because they do not usually make up for this restriction via alternative lexical means such as participles (cf. example (2) above without en volant). Differences in coding of path are, for instance, shown in Slobin (1996b), where downward motion is described only through the verb, i. e. without additional locative/directional elements, in $36 \%$ of Spanish narrators' propositions but only $15 \%$ of corresponding cases in English. Differences in coding of manner are, for instance, noted in Slobin (2003), where $69 \%$ of Russian narrators' motion verb tokens lexicalize manner elements as opposed to only $30 \%$ of such tokens in Hebrew narratives. Similarly, Özçalışkan/Slobin (2003) noted 64 different manner verbs in English novels but only 26 such verbs in Turkish novels. In fact, each manner coding verb in Turkish corresponds to at least two such verbs in English and as high as 17 in the case of yürü (compare to English translational equivalents such as walk, pace and sneak). As the manner lexicon is taken more generally to be richer relative to path (and more open to coining of new items), speakers of Sframed languages have been found to use a more extensive motion verb lexicon in comparison to that which is available and, moreover, actually used in V-framed languages (cf., e. g., Berman/Slobin 1994; Cardini 2008; Slobin 1996b for English, Ragnarsdóttir/Strömqvist 2004 for the Scandinavian S-framed languages Icelandic and Swedish).

While findings on typologically determined habits of speech have turned out quite robust, it is interesting that the expected cross-linguistic differences are not always striking and, in a few cases, not observed at all. However, the factors affecting their emergence and their strength have not been systematically discussed or explored (cf., however, Slobin 2004b for such an attempt). Reflecting upon the relevant literature, we can nonetheless point out at least the following factors as being critical: the age of speakers, various discourse-related parameters, the type of motion events described, details of a language's structure, as well as biases in the collection and analysis of data.

More particularly, it is, for one, by now widely accepted that typological constraints need time to become established (cf., e. g., Berman/Slobin 1994 on speech habits as well as Lucy/Gaskins 2003 on non-verbal categorization preferences). However, the age at which they begin to affect habits of language use is still an open matter, particularly since it may differ across particular linguistic domains. In the domain of motion more particularly, which concerns us here, relatively early effects have been found, but with no consensus on the precise time of their emergence. While extensive evidence from elicited narratives has indicated cross-linguistic differences from the preschool period, it does not concern children younger than 3 or 4 years of age, who cannot yet participate in semi-experimental tasks due to their limited linguistic and cognitive capacities (e. g. Berman/Slobin 1994; Hickmann 2003; Özçalışkan/Slobin 1999). Evidence from a period earlier than 3 years is drawn from natural conversations, but it is more limited and has provided somewhat conflicting results. Choi/Bowerman's (1991) comparison of Korean and English revealed slower emergence of manner verbs in V-framed Korean from the second year of life. However, Hohenstein et al. (2004) did not report differences between English- and Spanish-speaking children before the latter part of the third year. More particularly, while children in both languages originally use similar motion verbs, mostly general path verbs like go, in similar syntactic frames (i.e. in utterance-final position), it is only from the age of $2 ; 8$ that path-related information is appended to motion verbs rather systematically in English alone. In addition, while the verb repertory is enriched in both languages with age, it includes in the end more manner lexemes in English and more path ones in Spanish. Reviewing evidence from various studies of narratives and conversations in the age range of 2-5 years, Slobin (2003) notes clear differences between English, on the one hand, and Spanish, French or Italian, on the other. For instance, in the conversations, 32 manner lexemes in English correspond to only a limited set of such verbs in the Path languages. Moreover, the verbs used in English code fine nuances of manner, but only crude such distinctions in the Romance languages (cf. the counterparts of jump, run and walk). Although the development of children's speech habits in a more advanced age range remains to be fully charted, Berman/Slobin (1994) found the first 
robust signs of English-speaking children attaining habits typical of adults (and more generally of Manner languages) only from 9 years. These habits include, for one, compact descriptions of path, such as conflation of the source and goal of motion in a single clause (cf. example (3) by a 9-year old from Berman/Slobin 1994: 162), as opposed to coding of the goal alone earlier in the preschool period.

(3) He pushed him off the side of the cliff into water. [9-year old]

They also include more extensive usage of manner verbs compared to an earlier period but also to children of the same age who speak V-framed languages.

Moreover, speaker habits can vary depending upon factors such as the type of discourse, its context and content. For one, typological effects have been noted more often in extended discourse rather than isolated sentences describing single motion events. For instance, in a study of children's and adults' narratives, Özçalışkan/Slobin (1999) noted a more abundant range of motion verb types, including twice as many manner ones, in English relative to Spanish. By contrast, in a study of short descriptions of motion events elicited from English- and Spanishspeaking adults, Naigles et al. (1998) reported, among various complex findings, a relatively narrow range of motion verb types and a similar repertory of manner ones in both languages. Secondly, the information mentioned by speakers seems to depend upon communicative exigencies, such as what they judge to be presupposed or not by their audience. Papafragou et al. (2006) found that speakers of Greek, which they see as a Path language not favoring manner information, were more likely to mention manner when this element could not be inferred. Finally, the range and types of events described have also been found to play a critical role. For instance, in the Naigles et al. (1998) study, typological effects in use of motion verbs emerged in descriptions elicited through videos more systematically than in those elicited through pictures. The former stimulus represents motion naturally, while in the static stimulus dynamic aspects of movements must be inferred by the speaker. Only the videos succeeded in eliciting more manner lexemes in English than in Spanish. In addition, resultative (or telic) boundary-crossing events, i. e. those with definite sources or end-points like running into/out of a building, were more likely to elicit path rather than manner verbal lexemes in Spanish relative to English, thus enhancing the more restricted signaling of manner information in Spanish descriptions. In fact, this effect was stronger with the videotaped stimuli.

The appearance of cross-linguistic differences also depends upon how they are measured, i. e. upon the unit of analysis. More particularly, evidence points strongly to the conclusion that they are more likely when counting tokens rather than types of expressions - typically verbs. For instance, Özçalışkan/Slobin (1999) observed systematic differences between Spanish and Turkish on the one hand and English on the other in manner verb tokens but not lexemes. In fact, token counts reflected typological differences at all age levels studied, from 3 to 11 years as well as in adults, while the type counts do so only at the age of 4 and in adults. Moreover, as partly noted above for the Naigles et al. (1998) study, tokens of verbs as well as peripheral to the verbs elements differed across English and Spanish systematically in expectable ways, whereas verb types did only in some cases.

Finally, findings on effects of the typology have turned out more complicated than those predicted by a simple distinction of $\mathrm{V}$ - and $\mathrm{S}$-framed languages. Although this dichotomy inspired extensive theoretical and empirical work, it may not adequately capture the precise effects of all existent languages upon speakers' choices. In fact, research has pointed out intratypological variation and has more generally raised the need for a more complex pattern of typological distinctions (cf. Slobin's 2004b summary). For instance, Chantyal is described by Noonan (2003) as a non-prototypical V-framed language. It certainly includes path verbs, for instance translational equivalents of exit and enter, and does not favor sentences describing resultative/telic motion with manner lexicalizing verbs (like the S-language pattern of English in example (1); cf., e.g., Aske 1989; Hickmann 2003; Naigles et al. 1998; Slobin 1997; Slobin/Hoiting 1994 and Talmy 1991, for this restriction in V-framed languages). However, it diverges from the $\mathrm{V}$-framed system in at least two ways. Its path verb lexicon is noticeably restricted, lacking for instance translational equivalents of ascend and descend; additionally, it has an elaborate system of locative case clitics and directional satellites corresponding to English up, down, etc. Indeed, Noonan found narratives in Chantyal more closely resembling those in English rather than Spanish (cf. Slobin 1996b, 1997), as they portrayed detailed trajectories of moving entities, for instance through collocations of path elements. This 
similarity of Chantyal speech habits with those of an S-framed language rather than the expected V-framed one is attributed to the availability of convenient S-type linguistic resources. Another example of a complication for the typological dichotomy is the serial-verb language Thai (cf. Zlatev/Yangklang 2004). While it lexicalizes path in verbs like English enter, exit, ascend and descend, it also includes several verbs which lexicalize a variety of subtle distinctions of manner like equivalents of English hyponyms of walk including tiptoe and wade. Moreover, Thai manner verbs can occur rather freely with resultative motion events as in S-framed languages. Based upon both theoretical description and empirical data, Zlatev/Yangklang (2004) conclude that Thai cannot be properly categorized as either V- or Sframed, but as representing a third typological pattern (cf. Slobin 2004b for Equipollentlyframed languages).

We here present three empirical studies comparing descriptions of motion across English and Greek, with two general aims. First of all, we wish to enrich the body of research investigating whether speech habits are shaped by typological differences, through a comparison of data from the well-studied English and the lesser-studied Greek. The two languages are assumed to code motion event components in different ways. More precisely, English is thought to be S-framed and Greek V-framed by all researchers. However, Talmy (2000: 66f.) is an interesting exception in arguing that Greek is equally capable of S-framing. In fact, Greek has been characterized as a Path language on the basis of both theoretical description and empirical evidence on speech habits. Papafragou et al. (2002, 2006; cf. also Papafragou/ Selimis 2007, 2009, 2010) have noted that change of location in Greek is mostly taken over by path verbs such as aneveno ('ascend'), kateveno ('descend'), beno ('enter') and vjeno ('exit'), while manner is subordinated or omitted altogether particularly with resultative/telic events (cf. also relevant remarks in Horrocks/Stavrou 2007; Markantonatou/Trapalis 2003; Méndez Dosuna 1997). Furthermore, in experimentally elicited short descriptions of isolated motion scenes, Papafragou et al. (2002, 2006; cf. also Papafragou/Selimis 2007, 2010) found that English speakers encode manner much more frequently than Greek speakers not only through the verb but also the verb phrase (e.g. in adverbs). Given unanimous consent that Greek includes extensive V-framed patterns, we here take it as sufficiently different from English for the empirical comparison we are undertaking. Nonetheless, its precise typological status remains open, since Talmy (2000: 66-67) provides Greek examples of S-framing as well, including elements he assumes to be satellites (e.g. ekso 'out' besides the verb vjeno 'exit'). Our empirical evidence may thus also contribute to issues of typological description, regarding Greek more particularly, but also intra-typological variation and the adequacy of the Vand S-framed dichotomy more generally (like the evidence from Chantyal and Thai above).

The second aim of our research is to explore more systematically factors suggested by previous research to interact with the typology in effecting speech habits. Therefore, our three studies are not merely cross-linguistic (essentially, cross-typological) but also developmental as well as based upon three different types of speech data. More specifically, we compare natural conversations between adults and children in the age range of $1 ; 8$ to $4 ; 6$ and two types of narratives elicited semi-experimentally from children aged 4, 7 and 10 years as well as adults. One narrative is based on a chain of static pictures, a discourse type extensively studied in the past chiefly within the well-known frog story framework of Berman/Slobin (1994). The second type of narrative is based on a film, a stimulus with dynamic motion events, which has been less often studied (cf., however, Hickmann 2006; Pourcel 2005). Spontaneous conversations have been the least-studied type of discourse, with the few existent studies (Choi/Bowerman 1991; Hohenstein et al. 2004; Slobin 2003) concerning mostly the age range of 1-5 years (cf. Slobin 2003 for adults as well). The differences across the three types of speech data will be described in more detail in subsequent sections but include at least the following: type of discourse, range and type of events, as well as presuppositions regarding what the listener knows about the situations described. The extensive age range of the speakers, from the second year of life to adults, allows us to trace more systematically how speech habits may be gradually shaped by language structure. In fact, we include an early and little-studied age span, for which inconclusive results have been obtained from previous studies, as noted above, regarding the beginnings of such habits. Finally, as we will analyze both types and tokens of expressions, our research can also contribute to methodological issues on how differences in speech habits can best be measured. 
In order to fulfill the two general aims of our research, i. e. searching for possible typologically constrained differences in habits of speech as well as for factors effecting their appearance and intensity, we need to answer the following more specific questions:

(a) Are motion events, in particular their path and manner components, encoded differently by English and Greek speakers? Are such differences in accord with previous claims on how S- and V-framed languages shape speech habits? Or are they more complicated given that Greek may also allow S-framing?

(b) Do possible cross-linguistic differences in coding of path and manner manifest themselves under all conditions, or does their appearance and intensity depend upon factors such as the means of measuring them, the type and communicative exigencies of the discourse, the range and type of motion events described and the age of speakers?

\section{Empirical Studies}

We describe the methods of collecting and analyzing data as well as the findings separately for each of our three empirical studies.

\subsection{Study 1: Picture Narratives}

\subsubsection{Method}

The narratives based on pictures were produced by 79 native speakers of English or Greek, specifically adults (age range: 25-35 years) and children aged 4, 7 and 10 years. Each age group in each language consists of 10 participants (roughly half males and half females), with the exception of the English-speaking 10-year olds where only nine informants were available for technical reasons. These narratives are more specifically elicited on the basis of a sequence of 30 colored $21 \times 29.7 \mathrm{~cm}$ pictures (two are illustrated in Appendix 1). This sequence represents the story of an imprisoned princess freed by someone whom her father is searching to find in order to thank him. The story was supposedly told for the benefit of the king who needs to solve the mystery of his daughter's savior, but in the presence of a researcher who had full access to the pictures. The interviewers showed the first four pictures to each participant, accompanying them with introductory descriptions (e.g. "Here is the main street of a town..."). Then, they showed the remaining pictures, one by one, asking the participants to describe what each of the two potential saviors of the princess, named $\mathrm{Mr}$. Blue and Mr. Red, were doing. If necessary, as turned out mostly with 4-year olds, the narration was pushed forward by questions such as "What happened?" or "What did they do?". The pages were turned over only after a comment was produced, but in a manner which allowed the participant simultaneous viewing of the current and the immediately preceding picture.

Narrative texts were transcribed in CHAT format (cf. MacWhinney 2000). They were analyzed both for use of verbs as well as additional expressions coding motion. The first we need to clarify are the criteria for selecting a body of motion verbs to be analyzed, which we apply to all three of our empirical studies. Given the fuzzy boundaries of motion verbs from other semantic types as well as their internal heterogeneity, we restricted our concern to what may be thought of as prototypical cases (cf. Cardini 2008; Hohenstein et al. 2004; Özçalışkan/ Slobin 2003 for similar choices; also Antonopoulou 1987; Bassea-Bezantakou 1992 on Greek motion verbs). More particularly, we searched for verbs denoting only self-propelled translocation of an entity, which is coded as a grammatical subject (this being Mr. Red or Mr. Blue in the picture narrative). Given consensus that these are indeed motion verbs, we concentrate upon them in order to facilitate comparison with studies of other languages, which frequently restrict their analyses to these types. Less prototypical cases raise various issues. For instance, a much discussed type are verbs of caused motion (e.g. put and the corresponding Greek $v a z o$ ). It is held that they lexicalize the means or result sub-events of motion (e.g. push and Greek katevazo 'take/bring down' respectively) rather than manner or path in the strict sense (cf. Papafragou/Selimis 2009), although they have not always been separated from verbs of self motion in previous research (e. g. Berman/Slobin 1994; Özçalışkan/Slobin 1999; Slobin 1996b). 
We then distinguished motion verbs into path or manner ones. However, this task did not prove straightforward particularly in Studies 2 and 3 where a greater variety of motion verbs was encountered. While this fact has not been fully faced in previous research, it may affect results to a more critical extent than realized. We decided to take as path verbs those lexicalizing direction (e.g. enter/beno), including deictic ones (e. g. come/erchome). Manner was widely defined in terms of more objective elements like motor pattern (e. g. fly/peto), degree of effort (e. g. clamber) and speed/rate (e.g. run/trecho), but also more subjective evaluative ones such as the slyness evocated in Greek kseghlistro ('escape/slip away') (for path and/or manner sub-components, cf. Cardini 2008; Hickmann 2003; Naigles et al. 1998; Narasimhan 2003; Özçalışkan/Slobin 1999, 2003; Slobin 2004b; Talmy 1985, 2000, among many others; cf. also Antonopoulou 1987; Bassea-Bezantakou 1992 for Greek). However, a few verbs turned out to conflate manner and path. This was, for instance, the case with the commonly used verb fall (and its Greek correspondent pefto), which has caused much discussion in previous work precisely because it seems to encode both components. We decided to take such verbs as manner ones, as long as they coded at least one manner element regardless of whether path was also implicated (following others on this, e. g. Oh 2003; Özçalışkan 2005: 243, note 8; Özçalışkan/Slobin 1999). In addition, we characterized a few verbs as neutral, because they did not encode any path or manner elements, for instance Greek emfanizome ('appear') and the semantically vague English get (when of course it encodes motion among its various uses) (e. g. Cardini 2007, 2008: 564). Finally, in order to check whether speakers code path and manner through alternate to the verb means, we also analyzed additional elements in the verb phrase: modifiers of the verb including satellites (e. g. out), adverbs (e. g. slowly) and prepositional phrases (e. g. towards the castle), as well as periphrastic verbs (e.g. Greek kano patinaz, literally 'do skating'). We distinguished these elements into manner, path and neutral on the basis of the same criteria employed for verbs. Both verbs and other expressions were analyzed in terms of types as well as tokens.

\subsubsection{Results and Discussion}

We now turn to the results, beginning with the analyses of verbal lexemes in Table 1 (cf. also Appendix 2). As expected, path is more than twice as frequent in Greek relative to English, both overall (18 vs. 8 types) as well as at each particular age. Rather unexpectedly, however, coding of manner hardly differs across the two languages, although it appears on the average slightly higher in English. The same holds for the overall motion verb lexicon, which is larger in the V-framed language rather than the S-framed one ( 25 vs. 20 types). Although the overall difference in the size of the lexicon is not impressive, it is interestingly stronger in children and decreases notably only in adults. In fact, at 10 years verb types are quite unexpectedly three times more frequent in Greek. The cross-linguistic difference also increases if we exclude from our consideration the infrequently used neutral verbs (cf. Table 2 below on their limited tokens), i. e. 22 lexemes in Greek relative to only 13 in English. The larger motion verb lexicon in Greek can be ascribed to two facts: the notably large repertory of path verbs relative to English and the quite restricted - and similar - repertory of manner verbs in both languages. It is moreover interesting that the manner lexicon does not increase with age in either language, as expected from previous indications that it expands later in development (e. g. Berman/Slobin 1994; Özçalışkan/Slobin 1999). This becomes even more notable when we compare with the path lexicon, which is enriched in both languages with age, although gradually in Greek and more abruptly in English adults (the latter also notably increasing their neutral verbs). 


\begin{tabular}{|l|cccc|cccc|}
\hline \multicolumn{1}{|c|}{ Age } & \multicolumn{5}{|c|}{ Greek } & \multicolumn{4}{c|}{ English } \\
\hline & Path & Manner & Neutral & Total & Path & Manner & Neutral & Total \\
4 & 8 & 3 & 0 & 11 & 3 & 4 & 0 & 7 \\
7 & 12 & 2 & 2 & 16 & 4 & 4 & 1 & 9 \\
10 & 13 & 3 & 2 & 18 & 2 & 3 & 1 & 6 \\
Adults & 17 & 2 & 3 & 22 & 8 & 4 & 7 & 19 \\
\hline Overall & 18 & 4 & 3 & 25 & 8 & 5 & 7 & 20 \\
\hline
\end{tabular}

Table 1: The number of path, manner and neutral verb types across languages and ages in the picture narratives $^{1}$

When we examine verb tokens in Table 2, differences across the two languages become more systematic than in the case of verb types and are, moreover, predictable from previous findings on typological constraints (including comparisons of English and Greek noted in the Introduction). They are also in accord with previous findings that such differences emerge more clearly when counting frequencies of verb forms rather than lexical types. In short, path verb tokens are more frequent in Greek and manner ones in English. More specifically, in the Greek data, path verbs are overwhelming, while manner ones are quite restricted (85\% vs. $14 \%)$. Path verbs also predominate in the English data, but the difference from manner ones is by far less notable compared to Greek (overall, $54 \%$ path and $42 \%$ manner). In fact, manner tokens even come to exceed path ones at 10 years in English. Furthermore, typological differences first arise at 7 years and do not essentially change in the more advanced age groups. Interestingly, proportions of path and manner tokens are nearly identical in the two languages at 4 years. At the age of 7, however, manner tokens are notably decreased in Greek to less than half, while they rise instead in English. The opposite trend holds for path tokens, whose proportion increases in Greek and decreases notably in English. In fact, the crosslinguistic differences are most marked at the age of 10 and continue in adults, even though manner verb tokens in English decrease somewhat in favor of neutral ones. The cross-linguistic difference in the case of path more particularly is further revealed when we examine the particular lexemes used. In English, they consist mainly of the commonly used deictics go and come, while in Greek we find a larger inventory of lexemes typical of $\mathrm{V}$-framed languages such as fevgho ('leave'), aneveno ('ascend') and prochoro ('advance'). Furthermore, it turns out most interesting that, in spite of the notable difference in the proportion of manner tokens after the age of 7 , only a few lexemes are involved. They are, moreover, semantically similar across the two languages: over $90 \%$ consist of run and the corresponding Greek trecho as well as walk and its correspondent perpato.

\begin{tabular}{|l|cccc|cccc|}
\hline Age & \multicolumn{4}{|c|}{ Greek } & \multicolumn{4}{c|}{ English } \\
\hline & Path & Manner & Neutral & Total N & Path & Manner & Neutral & Total N \\
4 & $71 \%$ & $29 \%$ & $0 \%$ & 122 & $70 \%$ & $30 \%$ & $0 \%$ & 122 \\
7 & $87 \%$ & $12 \%$ & $1 \%$ & 181 & $52 \%$ & $44 \%$ & $4 \%$ & 134 \\
10 & $89 \%$ & $9 \%$ & $2 \%$ & 152 & $45 \%$ & $54 \%$ & $1 \%$ & 133 \\
Adults & $87 \%$ & $9 \%$ & $4 \%$ & 146 & $52 \%$ & $40 \%$ & $9 \%$ & 198 \\
\hline Mean & $85 \%$ & $14 \%$ & $2 \%$ & 601 & $54 \%$ & $42 \%$ & $4 \%$ & 587 \\
\hline
\end{tabular}

Table 2: Distribution of path, manner and neutral verb tokens across languages and ages in the picture narratives

Results on use of elements besides the verb itself within the overall verb phrase reveal again quite expectable differences across the two languages in the coding of both path and manner. More particularly, for the analysis of path, we selected only five pictures because they seem to trigger prototypical motion verbs more systematically. We then distinguished motion verbs, regardless of whether they were characterized as path, manner or neutral, into bare and non-

\footnotetext{
${ }^{1}$ In this table and subsequent ones on verbal lexemes, the overall figures count verb types only once, even if encountered at more than one age level.
} 
bare (following, e. g., Engberg-Pedersen/Trondhjem 2004; Slobin 1996b). We took as nonbare those accompanied by locative/directional information (example (4)) and as bare those lacking such arguments (example (5)).

(4) Mister Blue then runs ehm past the church... [adult]

(5) Meta o kirios Ble efije. [10-year old]

afterwards the Mister Blue leave-3SG-PAST

'Then, Mister Blue left.'

As shown in Table 3, peripheral path elements are clearly more frequent in the S-framed language, as expected. However, they largely increase with age in both languages. More particularly, two thirds of the Greek verbs are bare, in fact totally so at 4 years. After the age of 7, path-related information begins to be added to the verbs in Greek, but non-bare verbs always remain less frequent than in English. This holds even at 10 years, when path arguments peak in Greek, reaching $58 \%$ of the total. In sharp contrast, English speakers accompany nearly two thirds of their verbs with peripheral path elements even as early as the age of 4, approaching $90 \%$ by 7 years. In fact, adult speakers of English elaborate on path at times by accumulating satellites and/or prepositional phrases around a single verb (example (6); cf. also previous relevant findings by Berman/Slobin 1994; Slobin 2004a, 2004b, among others).

$$
\begin{aligned}
& \text {... and then I saw erm Mister Blue head off down the road away from erm the green space } \\
& \text { where the castle is... [adult] }
\end{aligned}
$$

However, the path domain is in the end coded routinely in both languages, even though through different means. This is best seen in the fact that $86 \%$ of verb phrases in English include path modifiers such as satellites (cf. Table 3), while $85 \%$ of Greek verb phrases include a path verb (cf. Table 2 above).

\begin{tabular}{|l|c|ccc|}
\hline Age & Language & \multicolumn{3}{c|}{ Motion Verbs } \\
\hline \multirow{4}{*}{4} & Greek & Bare & Non-Bare & Total N \\
& English & $100 \%$ & $0 \%$ & 29 \\
& Greek & $36 \%$ & $64 \%$ & 44 \\
10 & English & $71 \%$ & $29 \%$ & 56 \\
& Greek & $11 \%$ & $89 \%$ & 54 \\
\multirow{4}{*}{ Adults } & English & $42 \%$ & $58 \%$ & 52 \\
& Greek & $4 \%$ & $96 \%$ & 48 \\
& English & $59 \%$ & $42 \%$ & 53 \\
Mean & Greek & $7 \%$ & $93 \%$ & 68 \\
& English & $64 \%$ & $36 \%$ & 190 \\
& & $14 \%$ & $86 \%$ & 214 \\
\hline
\end{tabular}

Table 3: Distribution of bare and non-bare motion verbs across languages and ages in the picture narratives

In order to search for manner elements in the overall verb phrase, we found it useful to separate, as in the case of verbs above, tokens of verb phrases coding only path (e. g. fevji 'he leaves') from those also coding manner (e.g. fevji vjastika 'he leaves in a hurry') and finally from merely neutral ones (e. g. ksanaemfanistike 'he reappeared'). In fact, we focused only upon Greek speakers in order to see whether they make up for their more limited verb tokens by coding manner through means such as adverbial phrases. As Table 4 shows, they do add indications of manner through such elements in roughly $20 \%$ of verb phrase tokens across all age groups (compare to only $14 \%$ Greek manner verbs in Table 2). However, they still code for manner notably less than English speakers do through verbs alone, i. e. in $42 \%$ of cases (cf. Table 2). Although we found it unnecessary to count alternate means of manner in English as well, they were definitely used, thus strengthening the cross-linguistic difference at least from 7 years on (cf., e. g., Özçalışkan/Slobin 2001 for similar data on Turkish in comparison to English). It is furthermore interesting that the highest proportion of manner information is provided in Greek by the 4-year olds, while it diminishes later, particularly at 10 years, and increases somewhat in adults. However, phrases coding only path predominate in 
all age groups, being more than twice as frequent as those coding manner even at 4 years and at least four times more frequent after 7 years.

\begin{tabular}{|l|cccc|}
\hline \multicolumn{1}{|c|}{ Age } & \multicolumn{4}{c|}{ Verb Phrases } \\
\hline & Path & Manner & Neutral & Total N \\
4 & $69 \%$ & $31 \%$ & $0 \%$ & 124 \\
7 & $83 \%$ & $17 \%$ & $0 \&$ & 183 \\
10 & $88 \%$ & $12 \%$ & $1 \%$ & 153 \\
Adults & $80 \%$ & $19 \%$ & $1 \%$ & 152 \\
\hline Mean & $81 \%$ & $19 \%$ & $0 \%$ & 612 \\
\hline
\end{tabular}

Table 4: Distribution of path, manner and neutral verb phrases in Greek across ages in the picture narratives

In sum, the picture narratives revealed expectable cross-linguistic differences quite systematically in tokens of motion expressions but not in verb types. In terms of both verb and verb phrase frequencies, coding of manner is clearly privileged in English from 7 years onward, while path is highly codable in both languages even though through different means. As expected, Greek speakers opt for path verbs, while English speakers make extensive use of path elements besides the verb even at 4 years. In verb types, however, while Greek speakers use more path verbs as expected, the manner lexicon is quite restricted and similar in both languages.

\subsection{Study 2: Film Narratives}

\subsubsection{Method}

The film narratives were elicited from 79 speakers, allocated across languages and age groups as in Study 1 (though four of these 79 participants differed across the two studies). These narratives were based on a five-minute silent cartoon showing an adventure of a boy and his dog. In brief, these characters decide to go ice-skating on a frozen pond, but with only one pair of skates. While the child is skating, the ice cracks and he falls into the water. The dog saves him using a ladder and a scarf. In the end, they return home safe. The participants told the story to an interlocutor who had not watched the film and was thus naïve as to the story, triggered by the following question: "You just saw a film that I have not seen, could you tell me what happened in it?". The interlocutor intervened as little as possible. The data were analyzed following the procedure outlined in Section 2.1.1 for the picture narratives.

\subsubsection{Results and Discussion}

Results show motion verbs varying across the two languages on more measures and ages in more expectable ways relative to Study 1 . To begin with, cross-linguistic differences in the overall range of motion lexemes are now the reverse of those in Study 1 (cf. Table 5 and Appendix 3). Quite expectedly given previous results, English speakers use roughly twice as many lexemes relative to Greek speakers (overall, 44 vs. 24), even though the difference becomes salient only in adults. Examining more particularly the kinds of lexemes produced, we note, for one, that neutral ones are quite negligible relative to Study 1 even in English. Moreover, Greek speakers use, as they did in the picture story, more path lexemes than English speakers (14 types vs. 9 types). The opposite holds for manner ones, which are more than three times higher in the S-framed language (32 types relative to only 9 types in Greek). In fact, these cross-linguistic differences are discerned as early as 4 years and seem to increase with age, as path verbs rise in Greek and manner verbs in English (notwithstanding an "end-state" increase of path verbs as well in the latter language). Manner lexemes are on average twice as frequent in English relative to Greek during childhood, spurting to eight times more frequent in adults. It is furthermore interesting that the manner verbs come to be restricted to only three in Greek adults, i. e. ghlistro ('slip'), pefto ('fall') and trecho ('run'), with the first two being the commonest manner verbs in the Greek film narratives. By contrast, English-speaking adults come to make even cognitively subtle distinctions of manner with their 24 lexemes, double those of the 7- and 10-year olds. For example, they 
distinguish at least six types of moving on foot through walk, hurry, pace, step, tiptoe and trot. The overall repertory of motion lexemes is strikingly expanded in English adults not only due to the notable expansion of manner lexemes but also path ones. The Greek repertory of motion lexemes has however expanded earlier, at 7 years, remaining the same subsequently.

\begin{tabular}{|l|cccc|cccc|}
\hline Age & \multicolumn{4}{|c|}{ Greek } & \multicolumn{4}{c|}{ English } \\
\hline & Path & Manner & Neutral & Total & Path & Manner & Neutral & Total \\
4 & 5 & 4 & 0 & 9 & 2 & 9 & 1 & 12 \\
7 & 9 & 7 & 1 & 17 & 4 & 12 & 2 & 18 \\
10 & 11 & 6 & 0 & 17 & 2 & 13 & 1 & 16 \\
Adults & 13 & 3 & 1 & 17 & 8 & 24 & 2 & 34 \\
\hline Overall & 14 & 9 & 1 & 24 & 9 & 32 & 3 & 44 \\
\hline
\end{tabular}

Table 5: The number of path, manner and neutral verb types across languages and ages in the film narratives

As Table 6 shows, the cross-linguistic asymmetry in use of verb types can also be discerned in verb tokens, contrary to the discrepancy between the two measures in Study 1. Overall, English speakers pick manner verbs twice as frequently as Greek speakers (45\% vs. $26 \%$ ). Even though in the English data manner verbs are roughly equal to path ones on the average of the four age groups, they are roughly three times less frequent than path lexemes in the Greek data $(26 \%$ to $73 \%)$. While again the most frequent path verbs in English are go and come, in Greek we find a more extensive range, with the five most frequent being pao ('go'), vjeno ('exit'), jirizo ('return'), beno ('enter') and fevgho ('leave'). Roughly the opposite holds for manner verbs, which are definitely more diverse than those of Study 1 . Whereas the most frequent types in English are fall, skate, slip, walk, ice-skate and climb, in Greek we find mainly pefto ('fall'). Finally, the few neutral verbs are relatively frequent only in English, particularly at 4 years.

Moreover, the cross-linguistic asymmetry emerges earlier than in the picture narratives, at the age of 4 rather than 7, and continues in subsequent age groups. In fact, we note differences in the developmental trends of path and manner verb use across the two languages. For one, in Greek, the proportion of manner and path verbs remains the same from 4 to 7 years, but changes rather notably at 10 years, when manner verbs increase and in fact reach their peak. Quite interestingly, manner verbs drop to nearly half in adults, where path verbs rise once again. Therefore, as in the picture narratives, we discern signs of an "end-state" curtailment of manner information in the Path language. By contrast, in English, manner verbs already exceed path ones at the age of 4, unlike in Study 1 where the same is noted only at 10 years. However, by 7 they are somewhat curtailed, remaining at a similar proportion until adulthood. Path verbs, on the other hand, rise notably at 7, remaining roughly the same at 10 and slightly diminishing in adults.

\begin{tabular}{|l|cccc|cccc|}
\hline Age & \multicolumn{4}{|c|}{ Greek } & \multicolumn{4}{c|}{ English } \\
\hline & Path & Manner & Neutral & Total & Path & Manner & Neutral & Total \\
4 & $75 \%$ & $25 \%$ & $0 \%$ & 32 & $33 \%$ & $54 \%$ & $13 \%$ & 48 \\
7 & $74 \%$ & $25 \%$ & $1 \%$ & 117 & $50 \%$ & $45 \%$ & $6 \%$ & 145 \\
10 & $65 \%$ & $35 \%$ & $0 \%$ & 106 & $51 \%$ & $43 \%$ & $6 \%$ & 108 \\
Adults & $79 \%$ & $19 \%$ & $2 \%$ & 104 & $46 \%$ & $45 \%$ & $9 \%$ & 295 \\
\hline Mean & $73 \%$ & $26 \%$ & $1 \%$ & 359 & $47 \%$ & $45 \%$ & $8 \%$ & 596 \\
\hline
\end{tabular}

Table 6: Distribution of path, manner and neutral verb tokens across languages and ages in the film narratives

When we analyze means of coding manner and path alternative to the verb, findings turn out more complicated than expected. For one, Greek speakers make up, to some extent, for the relative lack of manner information shown in the analyses of verbs above. Manner is coded in $39 \%$ of their verb phrases (cf. Table 7), as opposed to only $26 \%$ of their verbs (cf. Table 6). More particularly, manner verb phrases increase with age in children, peaking in fact at 10 years as also noted in verb frequencies. In fact, at this age, coding of manner even surpasses 
the corresponding proportion in English (51\% vs. $44 \%$ ). Interestingly however, once again we note restriction of manner information in Greek adults to the level of 4-year olds $(30 \%)$. Although overall Greek speakers use more alternative means of coding manner than English speakers, they still provide more restricted information on manner (overall, $39 \%$ vs. $47 \%$ ). Moreover, these means include in Greek largely periphrastic verbs, mainly kano patinaz (literally, 'do skating') for a basic in the story event, as there is no monomorphemic verb in Greek corresponding to English skate.

\begin{tabular}{|l|cccc|cccc|}
\hline Age & \multicolumn{4}{|c|}{ Greek } & \multicolumn{4}{c|}{ English } \\
\hline & Path & Manner & Neutral & Total N & Path & Manner & Neutral & Total N \\
4 & $69 \%$ & $31 \%$ & $0 \%$ & 35 & $46 \%$ & $54 \%$ & $0 \%$ & 48 \\
7 & $62 \%$ & $38 \%$ & $0 \%$ & 138 & $53 \%$ & $46 \%$ & $1 \%$ & 147 \\
10 & $49 \%$ & $51 \%$ & $0 \%$ & 138 & $56 \%$ & $44 \%$ & $0 \%$ & 108 \\
Adults & $70 \%$ & $30 \%$ & $0 \%$ & 120 & $53 \%$ & $47 \%$ & $0 \%$ & 300 \\
\hline Mean & $61 \%$ & $39 \%$ & $0 \%$ & 431 & $53 \%$ & $47 \%$ & $0 \%$ & 603 \\
\hline
\end{tabular}

Table 7: Distribution of path, manner and neutral verb phrases across languages and ages in the film narratives

For the coding of path, we analyzed once again only five episodes and distinguished verbs into bare and non-bare. Rather surprisingly given the picture narratives and previous crosstypological studies, path was extensively encoded through elements such as satellites and prepositional phrases in both languages (cf. Table 8 as well as examples (7) and (8) with in and mesa sto spiti respectively). In fact, such alternative coding of path is observed in nine of 10 tokens on the average in Greek and nearly all in English. This cross-linguistic similarity remains relatively strong, even when we examine each age level separately. The greatest discrepancy between the two languages is noted at 7 years, but even here Greek speakers code path in roughly eight of 10 verb phrase tokens, while the greatest similarity is noted at 4 and 10 years.

(7) $\quad \ldots$ the girl went in to get some ice skates... [10-year old]

$$
\begin{aligned}
& \text {...bike mesa sto spiti... [adult] } \\
& \text { enter-3SG-PAST inside to.the house }
\end{aligned}
$$

Of course, given relatively high lexicalization of path in Greek, coding of this notion seemed at times redundant, as in example (8) above where the notion of 'inside' is lexicalized in the

\begin{tabular}{|c|c|c|c|c|}
\hline Age & \multirow[t]{2}{*}{ Language } & \multicolumn{3}{|c|}{ Motion Verbs } \\
\hline \multirow{3}{*}{4} & & Bare & Non-Bare & Total N \\
\hline & Greek & $0 \%$ & $100 \%$ & 16 \\
\hline & English & $5 \%$ & $95 \%$ & 22 \\
\hline \multirow[t]{2}{*}{7} & Greek & $21 \%$ & $79 \%$ & 33 \\
\hline & English & $0 \%$ & $100 \%$ & 45 \\
\hline \multirow[t]{2}{*}{10} & Greek & $0 \%$ & $100 \%$ & 32 \\
\hline & English & $3 \%$ & $97 \%$ & 32 \\
\hline \multirow[t]{2}{*}{ Adults } & Greek & $13 \%$ & $87 \%$ & 38 \\
\hline & English & $0 \%$ & $100 \%$ & 65 \\
\hline \multirow[t]{2}{*}{ Mean } & Greek & $10 \%$ & $90 \%$ & 119 \\
\hline & English & $1 \%$ & $99 \%$ & 164 \\
\hline
\end{tabular}
verb (bike) but also the adverb or satellite according to Talmy (2000: 66-67) (mesa) (cf. Sinha/Kuteva 1995 on such constructions more generally).

Table 8: Distribution of bare and non-bare motion verbs across languages and ages in the film narratives

In sum, the film narratives reveal predictable cross-linguistic differences in coding of manner not only in tokens of verbs and verb phrases but also in verb types (in contrast to the similarity of types in Study 1). Furthermore, differences now emerged as early as 4 years 
(relative to 7 years in Study 1) and were reinforced in adults. Nonetheless, a U-shaped developmental curve is now observed in Greek, including interestingly a surpassing of English in manner information at 10 years. In coding of path, however, while once again this occurred overwhelmingly with elements besides the verb in English, Greek speakers did not restrict themselves to the verb, but massively coded locative/directional information through peripheral to the verb elements as well. From this point of view, they resembled speakers of $\mathrm{S}$-framed languages and not only $\mathrm{V}$-framed ones.

\subsection{Study 3: Spontaneous Conversations}

\subsubsection{Method}

Our last study seeks cross-linguistic differences in natural conversations of very young children with adults in the age range of $1 ; 8$ to $4 ; 6$. More specifically, we used 72 recorded hours from Katis' Greek longitudinal corpus of Anna (cf. Katis/Kantzou 2002) and 78 recorded hours from Brown's (1973) English corpora of Eve and Sarah (available from the CHILDES data base at http://childes.psy.cmu.edu). In order to make comparison feasible, by taking into account age spans and number of hours recorded, we found it convenient to compare Anna with Eve in the age range of $1 ; 8$ to $2 ; 2$. Since data was collected for Eve only up to the age of 2;3, we found Sarah's data most suitable for comparison in the age range of $2 ; 3$ to $4 ; 6$. We divided the latter period into two phases in order to uncover possible trends (for details on the three age ranges, cf. Table 9).

\begin{tabular}{|c|c|c|c|c|}
\hline Age Span & \multicolumn{2}{|c|}{ Greek } & \multicolumn{2}{|c|}{ English } \\
\hline $1 ; 8-2 ; 2$ & Anna & 22 hours & Eve & 22 hours \\
$2 ; 3-3 ; 5$ & & 26 hours & Sarah & 30 hours \\
$3 ; 6-4 ; 6$ & & 24 hours & & 26 hours \\
\hline
\end{tabular}

Table 9: The children and the number of recorded hours across three age spans

We analyzed both child and child-directed speech. However, we departed somewhat from the coding procedure of the two narrative studies. For one, we restricted our concern to verb types and did not examine tokens of verbs and other expressions for the following reasons. It turned out difficult to analyze tokens in this type of discourse, where the content of speech is not controlled and restricted as in the narratives. We found several tokens of expressions whose precise meaning could hardly be disambiguated in the particular context of use. The problem was attenuated in the English data, which was collected by different researchers and contextual information remains more insufficient than in the Greek data. For instance, we could not even decide in some cases whether a given use signaled self-propelled or caused motion (as with move in example (9)), much more manner or path.

Move Mommy Eve climb down. [Eve 1;8]

Secondly, we categorized our verbal lexicon into manner and path only. As neutral verbs tend to be more polysemous (e.g. the all-purpose verb get), it was not always easy to decide whether they take on a motion sense at all, given the insufficient contextual information.

\subsubsection{Results and Discussion}

Table 10 shows the number of verbal lexemes characterized as path or manner in each language and age span (cf. also Appendix 4). The repertory of lexemes increases with age in both languages, particularly in child speech. It is also overall more extensive in English (52 types vs. 44 types in Greek), although the difference is definitely more restricted than in the film narratives. In fact, it is not at all observed in child speech, where 40 lexemes are interestingly used in each language. Moreover, if we examine each age span separately, we even find Greek lexemes exceeding English ones in all three developmental periods in child speech and in the earliest two age spans in child-directed speech. In other words, it is only after the age of 3;6 that adults produce a slightly richer range of verbs in English relative to Greek. In addition, quite unexpectedly manner lexemes are more extensive than path ones not only in English (45 vs. 7) - as also found in Study 2 - but also in Greek (28 vs. 16 types). The strong presence of manner lexemes in Greek thus explains why the overall lexicon is not as 
restricted as typically expected of $\mathrm{V}$-framed languages. Yet, the prevalence of manner lexemes is overall more striking in English, where they are roughly six times more extensive than path ones, while the corresponding ratio in Greek is less than 2:1. Put differently, in the conversations we note higher salience of manner in both languages, without however eradication of cross-linguistic differences in lexicalizing manner and path in both child and child-directed speech. Quite interestingly, these differences emerge in child speech in the earliest age span of $1 ; 8$ to $2 ; 2$, even though the Greek-speaking child, Anna, is exposed to as many manner verbs as the English-speaking Eve (i.e. 18 types). While differences seem more intense with coding of path, they are further revealed in the details of how the manner lexicon develops. For one, new verbs added after the age of 2;3 overwhelmingly lexicalize manner in both languages, in accord with previous findings arguing for the later development of this component of motion (e.g. Choi/Bowerman 1991; Hohenstein et al. 2004). However, more manner verbs enter the English lexicon than the Greek one, particularly in child-directed speech ( 21 vs. only 5 types; 20 vs. 15 types in child speech). In addition, while manner verbs surpass path ones in the English child speech as much as eight times already in the age range of $1 ; 8$ to $2 ; 2$, the same holds in the Greek child's speech only after the age of $2 ; 3$ and with a much lower ratio.

\begin{tabular}{|c|c|c|c|c|c|}
\hline Age Span & Verb Type & \multicolumn{2}{|c|}{ Greek } & \multicolumn{2}{|c|}{ English } \\
\hline $1 ; 8-2 ; 2$ & $\begin{array}{l}\text { Path } \\
\text { Manner } \\
\text { Total }\end{array}$ & $\begin{array}{l}\text { CS } \\
10 \\
10 \\
20\end{array}$ & $\begin{array}{c}\text { CDS } \\
11 \\
18 \\
29\end{array}$ & $\begin{array}{r}\mathrm{CS} \\
2 \\
16 \\
18\end{array}$ & $\begin{array}{c}\text { CDS } \\
2 \\
18 \\
20\end{array}$ \\
\hline $2 ; 3-3 ; 5$ & $\begin{array}{l}\text { Path } \\
\text { Manner } \\
\text { Total }\end{array}$ & $\begin{array}{l}14 \\
19 \\
33\end{array}$ & $\begin{array}{l}15 \\
18 \\
33\end{array}$ & $\begin{array}{r}2 \\
22 \\
24\end{array}$ & $\begin{array}{r}4 \\
25 \\
29\end{array}$ \\
\hline $3 ; 6-4 ; 6$ & $\begin{array}{l}\text { Path } \\
\text { Manner } \\
\text { Total }\end{array}$ & $\begin{array}{l}14 \\
23 \\
37\end{array}$ & $\begin{array}{l}13 \\
15 \\
28\end{array}$ & $\begin{array}{r}4 \\
28 \\
32\end{array}$ & $\begin{array}{r}5 \\
26 \\
31\end{array}$ \\
\hline $\begin{array}{l}\text { Overall } \\
(1 ; 8-4 ; 6)\end{array}$ & $\begin{array}{l}\text { Path } \\
\text { Manner } \\
\text { Total }\end{array}$ & $\begin{array}{l}15 \\
25 \\
40\end{array}$ & $\begin{array}{l}15 \\
23 \\
38\end{array}$ & $\begin{array}{r}4 \\
36 \\
40\end{array}$ & $\begin{array}{r}6 \\
39 \\
45\end{array}$ \\
\hline & $\begin{array}{l}\text { Path } \\
\text { Manner } \\
\text { Total }\end{array}$ & \multicolumn{2}{|c|}{$\begin{array}{l}16 \\
28 \\
44\end{array}$} & \multicolumn{2}{|c|}{$\begin{array}{r}7 \\
45 \\
52\end{array}$} \\
\hline
\end{tabular}

Table 10: The number of manner and path verb types across languages and age spans in the conversations; CS: child speech, CDS: child-directed speech

In sum, the conversations have been analyzed only in terms of verb types, where previous research has shown cross-linguistic differences to be less likely than with verb tokens. Yet, we found such differences, a fact suggesting that in spontaneous speech differences in habits of describing motion may be stronger and earlier than in elicited narratives. In fact, they appear in our data from the second year of life, in accord with Choi/Bowerman's (1991) findings. It is quite interesting that the proportion of manner lexemes is at the same time higher in both languages relative to the narratives. Nonetheless, the predominance of manner verbs is not only less striking in the V-framed language but also a later emerging phenomenon relative to the $\mathrm{S}$-framed language.

\section{General Discussion and Conclusions}

We can summarize the heterogeneous details of our results as follows. On the one hand, sufficient evidence was provided across the three empirical studies for supporting previous claims as to typological constraints upon speakers' habits of describing motion events. More specifically, the higher salience of manner in the discourse of those speaking S-framed languages (e. g. Slobin 2000, 2003, 2004a, 2006) is once more corroborated. Overall, English speakers did encode manner more extensively than Greek speakers, even if this did not hold 
on all measures and ages. The same holds for the robust finding that path, the "core" notion of motion according to Talmy $(1991,2000)$, is highly codable across V- and S-framed languages (e. g. Slobin 2003: 162), even if preferably through different means. In our research, Greek speakers used a wider repertory of path verbs and more frequently than English speakers. The latter did, however, provide path information systematically through alternate means such as satellites, thus "compensating for" what is not readily codable in the verb root. On the other hand, it was shown that typological effects on speakers' tendencies for coding motion can be discerned to a greater or lesser degree across the different types of speech depending at least upon the following factors: how they are measured, the type, content and pragmatics of the discourse, the age of speakers as well as the specific lexical and grammatical tools of a language. We will now examine these claims and their significance in more detail.

For one, cross-linguistic differences in speech habits are more likely when measured in tokens of expressions - above all, verbs - relative to types, as shown in the two studies of narratives, in accord with previous research. Most interesting is the case of the picture narratives, where the range of manner lexemes hardly differs across the two languages, but frequencies of use do (also cf. the Naigles et al. 1998 study of picture-elicited short descriptions). In fact, speakers in both languages exploit practically two verbs (i.e. walk and run and their correspondents perpato and trecho), but in greater frequency in English. We can here recognize parallels with Cardini's (2008) findings from experimental tests on ease of lexical access, that, for some translational equivalents of widely used manner verbs including walk and run, English speakers produce more tokens than Italian speakers. He suggests that the greater number of tokens in the S-framed language cannot be ascribed solely to its wider repertory of manner lexemes but also to the greater entrenchment of such verbs in mental representations, given their higher frequency in everyday speech. We also surmise that when differences are systematically noted in verb types, as in the conversations and the film narratives, typological effects can be assumed with even greater safety and expected, of course, in tokens as well.

Secondly, the data have supported previous claims that lexicalization patterns of motion shape cross-linguistic differences in speech habits only gradually with age (e. g. Berman/Slobin 1994; Hohenstein et al. 2004). However, both the age at which differences emerge and how they subsequently develop depend not only upon how they are precisely measured but also on the particulars of the speech data studied. It is, for one, interesting that they emerged in the natural conversations earlier than in the Hohenstein et al. (2004) study of corresponding discourse in Spanish and English, but in accord with the findings of Choi/Bowerman (1991) on Korean and English. Moreover, they become overall sharper later in development, at least in coding of manner. Yet, developmental changes are not simply linear, but follow a Ushaped curve at times. The most interesting observation is that at 10 years cross-linguistic differences tend to be weakened in the film narratives. This suggests that the development of speech habits is determined by a complex interaction of factors, for which we can only offer suggestions here and which certainly call for more systematic research in the future.

More particularly, differences in coding of manner can overall be claimed to intensify with advancing age, both because manner information decreased in Greek and at the same time increased in English. The curtailment of manner in Greek is clearly noted in the film stories of adults, but begins much earlier, at 7 years, in the picture stories, where 10-year olds have already reached, in terms of verb frequencies, the low level of adults. In the conversations, we note it only in the child-directed speech of the more advanced developmental period, i. e. in the age range of $3 ; 6$ to $4 ; 6$. The apparent tendency of Greek speakers to conform to the habits of their path-oriented language can even more strongly be argued, if we take into account that the notion of manner seems to be cognitively more complex than that of path (e. g. CifuentesFérez/Gentner 2006; Pourcel 2003, 2004; also cf. Talmy 2000), with the manner lexicon expected to be enriched later in development (e. g. Berman/Slobin 1994; Choi/Bowerman 1991; Hickmann 2006; Hohenstein et al. 2004). Indeed, for a while manner information increases gradually even in Greek, clearly in the conversations of the preschool period, above all in child speech, but also in the film narratives, where it peaks at 10 years. Such details lead us to assume that typological effects can in some cases, the film narratives in our data, be established much later than the age of 9 which is suggested by previous findings (Berman/Slobin 1994). By contrast, differences in the case of path, which has been shown to be more universally codable, concern mainly the way it is signaled (as emphasized in Cifuentes-Férez/Gentner's 2006 experimental work with English and Spanish speakers and in 
Hickmann's 2006 study of English and French speakers), i.e. mostly through the verb in Greek or modifiers of the verb in English. In the narratives, where we examine the overall verb phrase, path information is more abundant relative to manner and roughly equally mentioned by Greek and English speakers. The cross-linguistic similarity is stronger in the film stories, especially at 10 years, when path modifiers are notably used even in Greek.

Finally, our results varied across the three types of speech data studied, as partly indicated in the previous paragraph as well. More particularly, cross-linguistic differences turned out earlier and stronger in spontaneous conversations over the film narrative and, in turn, the picture-based one. We believe that this can be ascribed to differences in the type, content and communicative exigencies of the discourse. These include the situational contexts of speech, which range from most ecological in Study 3 to least ecological in Study 1. As partly noted earlier, the picture narrative involves only a few monotonous movements, as it was originally designed for the purpose of investigating additive particles such as also (cf. Watorek et al. 2002), the film narrative includes a greater range of motion events and the conversations an even greater variety. In fact, in the pictures, movement must be inferred by the speaker on the basis of statically depicted events, while in the animated cartoon it is represented more naturally. Moreover, the picture story was told in the presence of a researcher who had access to the corresponding material, even if designed to be addressed to an imaginary interlocutor. In addition, each scene was slightly separated orally from the next, so that there was no naturally flowing cohesion of the narrative. By contrast, the film narrative was told to an interlocutor who had no information about the story and, additionally, in a more naturally flowing discourse style compared to the "build-up" style of the picture narrative. Finally, in the conversations, background knowledge conditions are more varied, as more varied contexts of talk are involved.

We believe that these differences affected speakers as follows. For one, they had fewer chances for exploiting their manner lexicons in the picture story, thus explaining the narrow and similar range of such verbs in both languages. In fact, the movements involved are not only restricted but also simple - rather than fine-grained -, like leaving, walking and running. The latter two are, moreover, thought of as default or "neutral" ways of human translocation (cf. Pourcel 2004; Slobin 1997: 459) and, therefore, the corresponding verbs are expected to be more frequent in use relative to more "expressive" lexemes such as swoop and scramble. More generally, it is only to be expected that dynamic details of motion are to some extent lost in picture depictions. By contrast, the film narrative and, above all, the conversations include several events like skating, slipping, jumping and flying, thus providing more chances for conveying manner information even to Greek speakers, much more so to English speakers. Interestingly at the same time, in the film narrative as opposed to the picture one, Greek speakers also notably exploited peripheral means of coding path - as did quite expectedly the English speakers as well. The somewhat surprising tendency of Greek speakers to also use non-bare verbs, including S-framed constructions of path, may be ascribed to at least two reasons. For one, the higher use of manner verbs often required path information to be coded outside the verb, as was often the case with the important for the story boundary-crossing event of the child falling into the water (cf. Greek mesa sto nero). In addition, as the interlocutor has no recourse to the cartoon whatsoever, narrators sense his/her need to fully understand the "whereabouts" of events, thus explicitly describing, for instance, the dog's moving into the house as 'entering into the house' (Greek example (8) earlier), even if this may sometimes be deemed redundant coding.

At this point, we find it necessary to note that the tendency of Greek speakers to exploit path elements peripheral to the verb in the film narrative means that this option is indeed offered by their language. This in fact supports Talmy's (2000) claim that Greek codes path not only through verbs but also satellites. However, we do not wish to go so far as to support his assumption that Greek is equipotential for S- and V-framing. If we can speak of satellites in this language, they seem non-prototypical. This is because in our narratives they appear less frequently than in English and in more restricted semantic-syntactic possibilities. For example, the counterparts of English collocations such as walk across and climb across are unnatural in Greek. This is typical of languages with V-type patterns, where combinations of manner verbs with telic path expressions are usually only marginally acceptable. In addition, while the word out (or outside), for instance, is found in 33 verb phrase types and many more tokens as a satellite in English (e.g. with climb, come, crawl as well as transitive verbs 
denoting caused motion such as push and shake), only six corresponding Greek verb phrase types with ekso, ap' ekso and/or ektos are found. Moreover, like other satellites in English, out codes notions besides concrete path including abstract senses (e.g. in call out and wave out; cf. Aske 1989; Narasimhan 2003; Talmy 1991, 2000), while abstract extensions of its basic meaning do not appear in Greek. Nonetheless, the extensive use of non-bare verbs in the Greek film stories supports the idea that typological patterns are not merely dichotomous, as several commentators have acknowledged. Our evidence thus argues for typological description of languages on a continuum of path or manner salience (e. g. Ibarretxe-Antuñano 2007 and Slobin 2004b). To conclude, Greek seems a V-framed language, which nonetheless allows more extensive than expected patterns in the expression of path, as has occasionally been noted for certain other V-languages as well (cf. Cardini 2008 for Italian, IbarretxeAntuñano 2004 for Basque and Noonan 2003 for Chantyal).

In short, we have strengthened previous claims of typologically constrained differences, showing that speakers of Greek and English tend to describe even the same motion events from a different angle. Greek speakers conform largely to V-framing patterns of coding motion, thereby downgrading manner relative to English speakers who typically conform to $\mathrm{S}$-framing ones. We have in fact enriched the data available on the lesser-studied Greek, as far as speech habits are concerned, more particularly by studying extended discourse rather than sentences generated in a single event context as in previous experimental studies. This data has also allowed us to contribute to issues of typological description. Moreover, the crosslinguistic differences were found to emerge in natural speech much earlier than in previous studies of elicited narratives at least, although they were at the same time shown to follow a non-linear development and to be established in some cases only late in adults. In the end, the varied results across the three types of speech, ages and measures do suggest that we can best trace the available resources of a language and their actual exploitation by speakers only through data from a variety of discourse types, communicative situations and ages. Further research is certainly needed in order to uncover the full range of factors affecting the coding of motion and their relative importance in greater detail, particularly since the number of participants at each age level was relatively limited in our empirical studies.

\section{References}

Antonopoulou, Eleni (1987): Prototype Theory and the Meaning of Verbs, with Special Reference to Modern Greek Verbs of Motion. PhD Dissertation, SOAS, University of London.

Aske, Jon (1989): "Path Predicates in English and Spanish. A Closer Look". Proceedings of the Annual Meeting of the Berkeley Linguistics Society 15: 1-14.

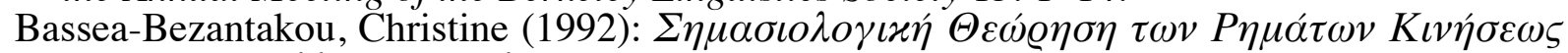

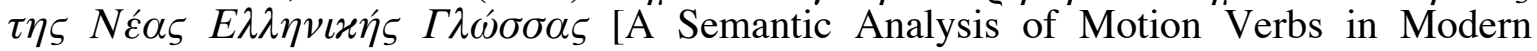
Greek]. Athens.

Berman, Ruth A./Slobin, Dan I. (eds.) (1994): Relating Events in Narrative. A Crosslinguistic Developmental Study. Hillsdale.

Brown, Roger (1973): A First Language. The Early Stages. Cambridge MA.

Cardini, Filippo-Enrico (2007): "Satellite-Framed vs. Verb-Framed Languages". Paper presented at the $10^{\text {th }}$ International Cognitive Linguistics Conference Kraków 2007.

Cardini, Filippo-Enrico (2008): "Manner of Motion Saliency. An Inquiry into Italian". Cognitive Linguistics 19/4: 533-569.

Choi, Soonja/Bowerman, Melissa (1991): "Learning to Express Motion Events in English and Korean. The Influence of Language-Specific Lexicalization Patterns". Cognition 41/1-3: 83-121.

Cifuentes-Férez, Paula/Gentner, Dedre (2006): "Naming Motion Events in Spanish and English". Cognitive Linguistics 17/4: 443-462.

Engberg-Pedersen, Elisabeth/Trondhjem, Frederikke B. (2004): "Focus on Action in Motion Descriptions. The Case of West-Greenlandic". In: Strömqvist, Sven/Verhoeven, Ludo (eds.): Relating Events in Narrative. Typological and Contextual Perspectives. Mahwah: 59-88.

Hickmann, Maya (2003): Children's Discourse. Person, Space and Time across Languages. Cambridge. 
Hickmann, Maya (2006): "The Relativity of Motion in First Language Acquisition". In: Hickmann, Maya/Robert, Stéphane (eds.): Space in Languages. Linguistic Systems and Cognitive Categories. Amsterdam: 281-308.

Hohenstein, Jill M./Naigles, Letitia R./Eisenberg, Ann R. (2004): "Keeping Verb Acquisition in Motion. A Comparison of English and Spanish". In: Hall, Geoffrey D./Waxman, Sandra R. (eds.): Weaving a Lexicon. Cambridge MA: 567-602.

Horrocks, Geoffrey C./Stavrou, Melita (2007): "Grammaticalized Aspect and SpatioTemporal Culmination". Lingua 117/4: 605-644.

Ibarretxe-Antuñano, Iraide (2004): "Motion Events in Basque Narratives". In: Strömqvist, Sven/Verhoeven, Ludo (eds.): Relating Events in Narrative. Typological and Contextual Perspectives. Mahwah: 89-111.

Ibarretxe-Antuñano, Iraide (2007): "Lexicalisation Patterns in Motion Events: Clines or Dichotomies?" Paper presented at the $10^{\text {th }}$ International Cognitive Linguistics Conference Kraków 2007.

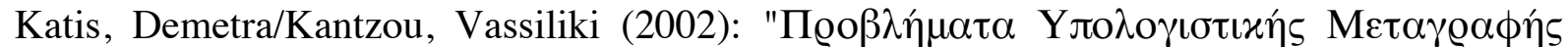

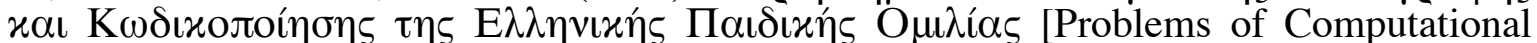
Transcription and Coding Greek Child Speech]". Studies in Greek Linguistics 22/2: 72-80.

Lucy, John A./Gaskins, Suzanne (2003): "Interaction of Language Type and Referent Type in the Development of Nonverbal Classification Preferences". In: Gentner, Dedre/GoldinMeadow, Susan (eds.): Language in Mind. Advances in the Study of Language and Thought. Cambridge MA: 465-492.

MacWhinney, Brian (2000): The CHILDES Project. Tools for Analyzing Talk. Mahwah.

Markantonatou, Stella/Trapalis, Giorgos (2003): "Modern Greek Verbs of Contact through Motion. A Study in the Compatibility of Semantic Factors and their Reflexes on the Syntax". Studies in Greek Linguistics 23/2: 658-668.

Méndez Dosuna, Julián (1997): "Fusion, Fission, and Relevance in Language Change. DeUniverbation in Greek Verb Morphology". Studies in Language 21/3: 577-612.

Naigles, Letitia R. et al. (1998): "Speaking of Motion. Verb Use in English and Spanish". Language and Cognitive Processes 13/5: 521-549.

Narasimhan, Bhuvana (2003): "Motion Events and the Lexicon. A Case Study of Hindi". Lingua 113/2: 123-160.

Noonan, Michael (2003): "Motion Events in Chantyal". In: Shay, Erin/Seibert, Uwe (eds.): Motion, Direction and Location in Languages. Amsterdam: 211-234.

Oh, Kyung-ju (2003): "Manner and Path in Motion Event Descriptions in English and Korean". In: Beachley, Barbara/Brown, Amanda/Conlin, Frances (eds.): Proceedings of the Annual Boston University Conference on Language Development. Somerville: 580590. (= BUCLD 27/2).

Özçalışkan, Şeyda (2005): "Metaphor Meets Typology. Ways of Moving Metaphorically in English and Turkish". Cognitive Linguistics 16/1: 207-246.

Özçalışkan, Şeyda/Slobin, Dan I. (1999): "Learning 'How to Search for the Frog'. Expression of Manner of Motion in English, Spanish, and Turkish". In: Greenhill, Annabel/Littlefield, Heather/Tano, Cheryl (eds.): Proceedings of the Annual Boston University Conference on Language Development. Somerville: 541-552. (= BUCLD 23/2).

Özçalışkan, Şeyda/Slobin, Dan I. (2001): "Interplay between Semantic Codability and Alternative Lexical Means in Children's Motion Event Descriptions". Poster presented at the $37^{\text {th }}$ International Chicago Linguistic Society Conference Chicago IL 2001.

Özçalışkan, Şeyda/Slobin, Dan I. (2003): "Codability Effects on the Expression of Manner of Motion in Turkish and English". In: Özsoy, Sumru A. et al. (eds.): Studies in Turkish Linguistics. Istanbul: 259-270.

Papafragou, Anna/Massey, Christine/Gleitman, Lila (2002): "Shake, Rattle, 'n' Roll. The Representation of Motion in Language and Cognition". Cognition 84/2: 189-219.

Papafragou, Anna/Massey, Christine/Gleitman, Lila (2006): "When English Proposes What Greek Presupposes. The Cross-Linguistic Encoding of Motion Events". Cognition 98/3: B75-B87.

Papafragou, Anna/Selimis, Stathis (2007): "Lexical and Structural Cues for Acquiring Motion Verbs Cross-Linguistically". In: Caunt-Nulton, Heather/Kulatilake, Samantha/Woo, I-hao (eds.): Proceedings of the Annual Boston University Conference on Language Development. Somerville: 485-496. (= BUCLD 31/2). 
Papafragou, Anna/Selimis, Stathis (2009): "On the Acquisition of Motion Verbs CrossLinguistically". Proceedings of the $8^{\text {th }}$ International Conference on Greek Linguistics: 351-365. Available at http://www.linguist-uoi.gr/cd_web/arxiki_en.html. Accessed September $5^{\text {th }}, 2009$.

Papafragou, Anna/Selimis, Stathis (2010): "Event Categorization and Language. A CrossLinguistic Study of Motion". Language and Cognitive Processes 25/2: 224-260.

Pourcel, Stéphanie (2003): "Rethinking 'Thinking for Speaking'". Proceedings of the Annual Meeting of the Berkeley Linguistics Society 29: 349-358.

Pourcel, Stéphanie (2004): "What Makes Path of Motion Salient?" Proceedings of the Annual Meeting of the Berkeley Linguistics Society 30: 505-516.

Pourcel, Stéphanie (2005): "Linguistic Relativity in Cognitive Processes". Paper presented at the $1^{\text {st }}$ UK Cognitive Linguistics Conference Sussex 2005.

Ragnarsdóttir, Hrafnhildur/Strömqvist, Sven (2004): "Time, Space, and Manner in Swedish and Icelandic. Narrative Construction in Two Closely Related Languages". In: Strömqvist, Sven/Verhoeven, Ludo (eds.): Relating Events in Narrative. Typological and Contextual Perspectives. Mahwah: 113-157.

Sinha, Chris/Kuteva, Tania (1995): "Distributed Spatial Semantics". Nordic Journal of Linguistics 18/2: 167-199.

Slobin, Dan I. (1996a): "From 'Thought and Language' to 'Thinking for Speaking'". In: Gumperz, John J./Levinson, Stephen C. (eds.): Rethinking Linguistic Relativity. Cambridge: 7096.

Slobin, Dan I. (1996b): "Two Ways to Travel. Verbs of Motion in English and Spanish". In: Shibatani, Masayoshi/Thompson, Sandra A. (eds.): Grammatical Constructions. Their Form and Meaning. Oxford: 195-217.

Slobin, Dan I. (1997): "Mind, Code, and Text". In: Bybee, Joan/Haiman, John/Thompson, Sandra A. (eds.): Essays on Language Function and Language Type. Dedicated to T. Givón. Amsterdam: 437-467.

Slobin, Dan I. (2000): "Verbalized Events. A Dynamic Approach to Linguistic Relativity and Determinism". In: Niemeier, Susanne/Dirven, René (eds.): Evidence for Linguistic Relativity. Amsterdam: 107-138.

Slobin, Dan I. (2003): "Language and Thought Online. Cognitive Consequences of Linguistic Relativity". In: Gentner, Dedre/Goldin-Meadow, Susan (eds.): Language in Mind. Advances in the Study of Language and Thought. Cambridge: 157-191.

Slobin, Dan I. (2004a): "How People Move. Discourse Effects of Linguistic Relativity". In: Moder, Carol Lynn/Martinović-Zić, Aida (eds.): Discourse across Languages and Cultures. Amsterdam: 195-210.

Slobin, Dan I. (2004b): "The Many Ways to Search for a Frog. Linguistic Typology and the Expression of Motion Events". In: Strömqvist, Sven/Verhoeven, Ludo (eds.): Relating Events in Narrative. Typological and Contextual Perspectives. Mahwah: 219-257.

Slobin, Dan I. (2006): "What Makes Manner of Motion Salient? Explorations in Linguistic Typology, Discourse, and Cognition". In: Hickmann, Maya/Robert, Stéphane (eds.): Space in Languages. Linguistic Systems and Cognitive Categories. Amsterdam: 59-81.

Slobin, Dan I./Hoiting, Nini (1994): "Reference to Movement in Spoken and Signed Languages. Typological Considerations". Proceedings of the Annual Meeting of the Berkeley Linguistics Society 20: 487-505.

Strömqvist, Sven/Verhoeven, Ludo (eds.) (2004): Relating Events in Narrative. Typological and Contextual Perspectives. Mahwah.

Talmy, Leonard (1985): "Lexicalization Patterns. Semantic Structure in Lexical Forms". In: Shopen, Timothy (ed.): Language Typology and Syntactic Description. Vol. 3: Grammatical Categories and the Lexicon. Cambridge: 57-149.

Talmy, Leonard (1991): "Path to Realization. A Typology of Event Conflation". Proceedings of the Annual Meeting of the Berkeley Linguistics Society 17: 480-519.

Talmy, Leonard (2000): Toward a Cognitive Semantics. Vol. 2: Typology and Process in Concept Structuring. Cambridge MA.

Watorek, Marzena/Lambert, Monique/Perdue, Clive (2002): Construction du Discours par des Apprenants des Langues, Enfants et Adultes. Rapport Final du Projet APN 2JE 454 (Section du Comité National 34 du CNRS). Unpublished report. 
Zlatev, Jordan/Yangklang, Peerapat (2004): "A Third Way to Travel. The Place of Thai in Motion-Event Typology". In: Strömqvist, Sven/Verhoeven, Ludo (eds.): Relating Events in Narrative. Typological and Contextual Perspectives. Mahwah: 159-190.

\section{Appendix 1: Two Scenes from the Picture Story}
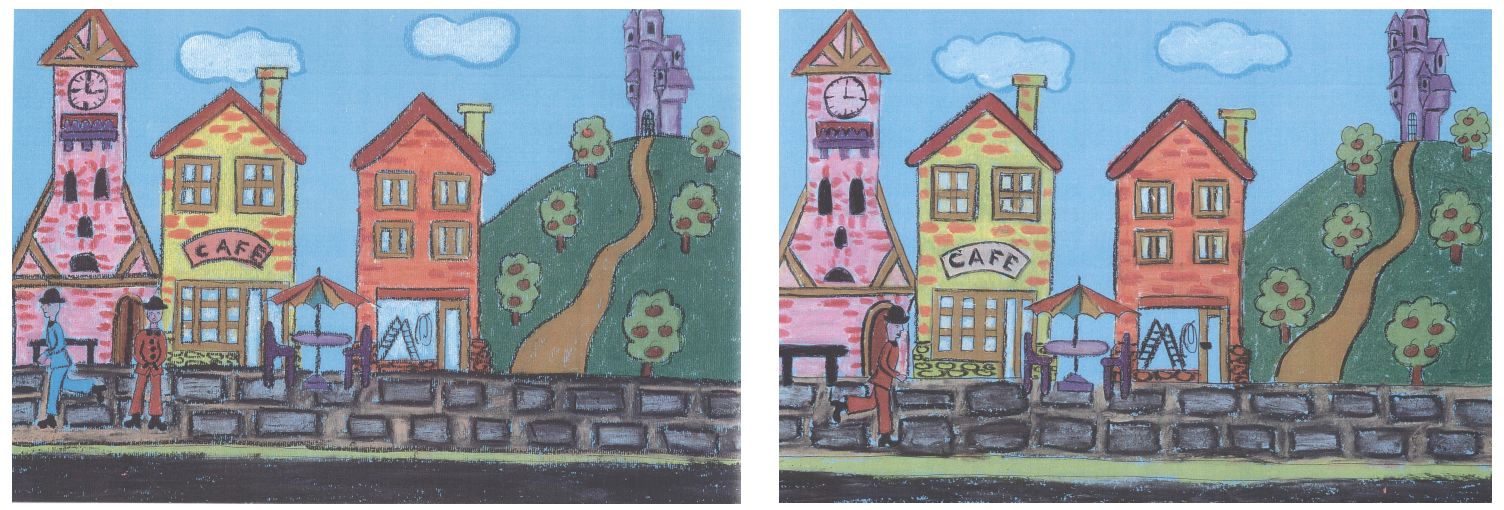

\section{Appendix 2: Lists of Motion Verbs in the Picture Narratives in Each Language}

Greek

Path verbs: $\quad$ akoloutho 'follow', aneveno 'ascend', apomakrinome 'move away', apochoro 'withdraw', vjeno 'exit', jirizo 'come back', epistrefo 'return', erchome 'come', kateveno 'descend', katefthinome 'head for', beno 'enter', ksekino 'start off', pao/pijeno 'go', perno 'pass', plisiazo 'approach', prochoro 'advance', fevgho 'leave', ftano 'arrive'

Manner verbs: vadhizo 'walk', perpato 'walk', skarfalono 'climb up', trecho 'run'

Neutral verbs: vriskome 'be found (on/in/at)', emfanizome 'appear', sinechizo 'continue'

English

Path verbs:

Manner verbs:

come, enter, go, head (for), leave, pass, proceed, return

climb, drive, fall, run, walk

Neutral verbs:

carry (on), continue, disappear, get, move, reappear, start (out)

\section{Appendix 3: Lists of Motion Verbs in the Film Narratives in Each Language}

Greek

Path verbs: aneveno 'ascend', vjeno 'exit', jirizo 'come back', epistrefo 'return', erchome 'come', kataligho 'reach/end up', kateveno 'descend', beno 'enter', ksekino 'start off', pao/pijeno 'go', perno 'pass', prochoro 'advance', fevgho 'leave', ftano 'arrive'

Manner verbs: vouliazo 'sink', vouto 'dive', ghlistro 'slip', ksefevgho 'slip away', pedhiklonome 'stumble', perpato 'walk', pefto 'fall', trecho 'run', chonome 'squeeze in'

Neutral verb: vriskome 'be found (on/in/at)'

English

Path verbs:

Manner verbs:

arrive, come, cross, follow, go, head, leave, pass, return

bounce, clamber, climb, crash, crawl, creep, fall, fly, hurry, ice-skate, jump, land, pace, be propelled, pull (back), run, scooter, scramble, skate, ski, slide, slip, spin, splash, step, be/get stuck, swim, tiptoe, be thrown, trip, trot, walk

Neutral verbs: get, move, set 


\section{Appendix 4: Lists of Motion Verbs in the Natural Conversations in Each Language}

\section{Greek}

Path verbs: akoloutho 'follow', aneveno 'ascend', vjeno 'exit', jirizo 'come back', erchome 'come', kateveno 'descend', beno 'enter', benovjeno 'go in and out', ksekino 'start off', pao/pijeno 'go', perno 'pass', plisiazo 'approach', prochoro 'advance', sikonome 'rise', fevgho 'leave', ftano 'arrive'

Manner verbs: vouliazo 'sink', vouto 'dive', ghlistro 'slip', jirizo 'roam around', kolibo 'swim', kilo 'roll', kilieme 'wallow', kinigho 'chase', bousoulo 'crawl', kseghlistro 'slip away', ksepidho 'jump out', ksefevgho 'slip away', odhigho 'drive', ormo 'rush', perpato 'walk', petaghome 'jump up', peto 'fly', pefto 'fall', pidho 'jump', sernome 'drag', skarfalono 'climb up', strifojirizo 'whirl around', taksidhevo 'travel', trecho 'run', tsoulao 'roll', chorevo 'dance', 'choropidho 'hop', chonome 'squeeze in'

English

Path verbs: come, cross, end, follow, go, leave, turn ('return')

Manner verbs: $\quad$ bob, bounce, bump, chase, climb, dance, dive, drive, drop, fall, float, flop, fly, hop, hunt, hurry, ice-skate, jive, jump, land, march, pop, race, ride, roll, roller-skate, row, run, scram, skate, skip, slide, slip, slow, sneak, step, swim, swing, tip, tiptoe, tramp, trip, turn ('whirl around'), walk, wander 